\title{
Knowledge and Practice of Self-medication among Undergraduate Medical Students
}

\author{
Anishma Karmacharya, a,d Bipashwi Nath Uprety,, ${ }^{\text {a,e }}$ Ravi Shankar Pathiyil, ${ }^{\text {b, }}$ Sudesh Gyawali ${ }^{\mathrm{c}, \mathrm{g}}$
}

Submitted: 6 February 2018

Accepted: 4 May 2018

Published: 13 May 2018

\begin{abstract}
:
Introduction: Self-medication is an important aspect of self-care. It is a common practice in society and medical students are no exception. The aim of this study was to explore the knowledge and practice of self-medication among students of a medical school in Western Nepal. Methods: A cross sectional study was conducted among basic science and clinical students after obtaining prior consent from those willing to participate. Respondents' degree of agreement with a set of 25 statements was noted using Likert scale to assess their knowledge. The practice of self-medication was studied by asking about the use of selected groups of medicines during the past one-year period and noting the pattern of use. Results: Three hundred and thirty of the 356 students (92.6\%) participated in the study. Mean knowledge score was $93.2(S D=8.1)$. Self-medication was practiced by $83.3 \%(n=275)$ of respondents. Knowledge about self-medication differed among respondents according to gender $(p=0.03)$ and nationality $(p=0.04)$ but not other variables. Practice of self-medication was associated with father's profession $(p=0.03)$ and nationality of the respondents $(p=0.04)$. Conclusions: Students' knowledge about self-medication was good and they commonly practiced self-medication. Pain-killers were the most commonly used drug.
\end{abstract}

Keywords: knowledge $\bullet$ medical students $\bullet$ Nepal $\bullet$ practice $\bullet$ self medication

\section{INTRODUCTION:}

Self-medication is an important element of self-care. It incorporates both selection and use of medicines including herbal preparations and traditional products for the treatment of self-identified illness or persistent use of the physician (or other

a - Lecturer, Department of Pharmacology

b - Professor, Department of Pharmacology

c - Associate Professor, Department of Pharmacology

d - Lumbini Medical College, Palpa, Nepal

e - Patan Academy of Health Sciences, Nepal

f - American International Medical University, Saint Lucia

g - Manipal College of Medical Sciences, Pokhara, Nepal

Corresponding Author:

Anishma Karmacharya

e-mail: karmacharya.anishma@gmail.com

ORCID: https://orcid.org/0000-0003-4621-1041

\section{How to cite this article:}

Karmacharya A, Uprety BN, Pathiyil RS, Gyawali S. Knowledge and practice of self-medication among undergraduate medical students. Journal of Lumbini Medical College. 2018;6(1):21-26. DOI: 10.22502/jlmc.v6i1.174. Epub: 2018 May 13 prescribers) prescribed medicines for chronic or recurring diseases.[1] Some adverse consequences of inappropriate self-medication can be: Incorrect self-diagnosis, failure to obtain the right medical consultation, incorrect treatment choice, failure to identify contraindications, interactions, adverse effects, inappropriate route and dosage, and risk of dependence.[2] However, responsible practice of self-medication can save medical resources, money, and the time spent on health care for minor illness. [3] Self-medication among medical students may be more common because they may have better knowledge about diseases and greater access to medicine.[4]

As the medical undergraduates are the future generation of prescribers, it is important to obtain information about their self-medication knowledge and practices.[3] But there is a paucity of recent information regarding self-medication practice among medical students in Western Nepal. Hence, this study was conducted to assess knowledge and practice of self-medication among undergraduate 
medical students of a Medical College in that region and note the variation in knowledge and practice of self-medication among different sub-groups of respondents, if any.

\section{METHODS:}

A cross-sectional study was conducted at Lumbini Medical College and Teaching Hospital (LMCTH) among medical undergraduates of second, fourth, sixth, and eighth semesters from April to July 2016. Data from respondents of second and fourth semesters were collected during April and May while those of sixth and eight semesters during June and July respectively. Convenience sampling technique was adopted to include all the students who were willing to participate. LMCTH is affiliated to Kathmandu University and conducts a five and a half years' Bachelors of Medicine and Bachelors of Surgery (MBBS) course as its core program.The program includes study of the basic sciences for two years, clinical study for two and a half years, and one year of compulsory rotating internship. The institution enrolls 100 students annually for the MBBS course.

The principal author collected the data from the respondents in the lecture halls during the breaks after the routine lecture hours. The purpose of the study and details on the questionnaire was explained to the respondents. After a verbal consent and assuring about the confidentiality of their information, the questionnaires were distributed to the respondents, asked to fill it up by themselves, and return it after thirty minutes.

The major tool for the study was a pretested questionnaire prepared after an extensive review of literature. A similar questionnaire was used before. $[1,5]$ In this study, certain modifications were carried out such that only knowledge was assessed but not perception as this term is abstract and statements may not be able to adequately study perception. Hence, the number of statements were reduced to 25 from 40 after excluding those which were supposed to assess perception in previous studies.[1,5]

The modified questionnaire consisted of two sections. First section obtained personal and background information about the participants. Second section had a set of twenty-five statements to assess the knowledge. The practice of selfmedication was studied by enquiring about the use of selected groups of medicines during the previous one year period and noting down the pattern of use.
[5] Analgesics, skin ointments, antipyretics, antiallergics, antibiotics, vitamins and tonics, ayurvedic medicines, and other group of drugs were studied. The respondents were asked whether they selfmedicated with any of the above mentioned drug or drugs during the previous one year. If their answer was yes, they were further enquired about how frequently they self-medicated (Nearly all the time, once a week, once a month, every three months, every six months).

For assessing knowledge, the respondents were asked to provide a score ranging from 1 to 5 (whole numbers only) according to their degree of agreement with each statement where 1 = strongly disagree, 2 = disagree, 3 = neutral, 4 = agree and, 5 = strongly agree. Statements seven and 12 were negatively worded and their scores reversed while calculating the total score to reduce bias. Knowledge was calculated by adding the scores of each of the 25 statements.

Reliability testing was done by a group of faculty members of LMCTH. Further, pretesting of the questionnaire was done among forty students of fifth semester who were not included in the study. Cronbach's alpha was calculated as a measure of reliability.

\section{Ethical clearance:}

Ethical clearance was obtained from the Institutional Review Committee (IRC) of LMCTH.

\section{Statistical analysis:}

The data entry and analysis was done using statistical package for social sciences (SPSS) version 16 for windows. One sample Kolmogorov Smirnov Test was used to check whether the data was normally distributed. Independent sample t-test was used to compare the mean scores between dichotomous variables, while analysis of variance (ANOVA) was used for groups with more than two subgroups. Pearson correlation was used to check the relation between two continuous variables while Chi-square test was used to check the association between two categorical variables. Statistical significance was allocated at a $p$ value less than 0.05 .

\section{RESULTS:}

A total of 330 out of 356 candidates responded to the study. Mean age was 20.83 years $(S D=1.7)$. Male respondents $(n=188,57 \%)$ outnumbered 
females ( $n=142,43 \%)$. Majority of the respondents ( $n=273,83 \%$ ) were Nepalese and belonged to urban areas $(n=274,83 \%)$. Most of the respondents' parents were from non-health related professions. Table 1 provides details of the respondents' demographic characteristics.

Knowledge score was found to follow a normal distribution by one-sample Kolmogorov-Smirnov test $(Z=1.5, p=0.08)$. Hence, mean was used as the measure of central tendency and standard deviation as the measure of variance. The overall mean knowledge score was $93.26(S D=8.16)$.

Relationship between mean knowledge score and various variables is shown in Table 2 . It shows that female students had a statistically significantly higher mean knowledge score as compared to that of male $(p=$ 0.03). Similarly, students who came to study medicine from India had significantly higher mean knowledge score as compared to Nepali students ( $p=0.03$ ). There was no statistically significant relationship between mean knowledge score and other variables like urban or rural background, father's profession, mother's profession, and semester of study.

Pearson correlation coefficient was calculated for the relationship between the age of the respondents and the knowledge score which indicated no significant linear relationship between those two variables $(r=$ $-0.34, p=0.53$, Figure 1).

A total of 275 respondents (83.3\%) were found to practice self-medication during past one year period. As shown in Table 3, the prevalence of self-

Table 1: Demographic profile of the respondents $(N=330)$

\begin{tabular}{|c|c|c|}
\hline Variables & & $n(\%)$ \\
\hline \multirow{2}{*}{ Gender } & Male & $188(57)$ \\
\hline & Female & $142(43)$ \\
\hline \multirow{2}{*}{ Nationality } & Nepalese & $273(83.6)$ \\
\hline & Indian & $54(16.4)$ \\
\hline \multirow{2}{*}{ Family Home } & Urban & 274 (83) \\
\hline & Rural & $56(17)$ \\
\hline \multirow{2}{*}{ Father's Profession } & Health related & 58 (17.6) \\
\hline & Non-health related & $272(82.4)$ \\
\hline \multirow{3}{*}{ Mother's Profession } & Health related & $28(8.5)$ \\
\hline & Non-health related & $162(49.1)$ \\
\hline & Housewife & $140(42.4)$ \\
\hline \multirow{4}{*}{ Semester of study } & Second & 87 (26.4) \\
\hline & Fourth & 96 (29.1) \\
\hline & Sixth & 75 (22.7) \\
\hline & Eighth & 72 (21.8) \\
\hline
\end{tabular}

Table 2: Mean knowledge score of self-medication among various subgroups of respondents $(N=330)$

\begin{tabular}{|c|c|c|c|}
\hline Variables & & Mean (SD) & Statistics \\
\hline \multirow{2}{*}{ Gender } & Male & $92.45(8.4)$ & \multirow{2}{*}{$\begin{aligned} t & =-2.10 \\
d f & =317.9 \\
p & =0.03\end{aligned}$} \\
\hline & Female & $94.32(7.6)$ & \\
\hline \multirow{2}{*}{ Nationality } & Nepalese & 91.07 (8) & \multirow{2}{*}{$\begin{array}{l}t=-2.09 \\
d f=73.1 \\
p=0.03\end{array}$} \\
\hline & Indian & $93.68(8.4)$ & \\
\hline \multirow{2}{*}{$\begin{array}{l}\text { Family } \\
\text { Home }\end{array}$} & Urban & $93.51(8.2)$ & \multirow{2}{*}{$\begin{array}{c}t=1.28 \\
d f=81.5 \\
p=0.2\end{array}$} \\
\hline & Rural & $92.02(7.8)$ & \\
\hline \multirow{2}{*}{$\begin{array}{l}\text { Father's } \\
\text { Profession }\end{array}$} & Health related & 93.17 (7) & \multirow{2}{*}{$\begin{array}{c}t=-0.98 \\
d f=95.3 \\
p=0.9\end{array}$} \\
\hline & Non-health related & 93.28 (8.3) & \\
\hline \multirow{3}{*}{$\begin{array}{l}\text { Mother's } \\
\text { Profession }\end{array}$} & Health related & $93.93(5.2)$ & \multirow{3}{*}{$\begin{array}{c}F=0.52 \\
d f=2 \\
p=0.59\end{array}$} \\
\hline & Non-health related & $93.60(8.5)$ & \\
\hline & Housewife & $92.73(8.2)$ & \\
\hline \multirow{4}{*}{$\begin{array}{l}\text { Semester of } \\
\text { study }\end{array}$} & Second & $92.94(8.1)$ & \multirow{4}{*}{$\begin{array}{c}F=1.82 \\
d f=3 \\
p=0.14\end{array}$} \\
\hline & Fourth & $94.80(7.7)$ & \\
\hline & Sixth & $92.03(9.1)$ & \\
\hline & Eighth & $92.86(7.3)$ & \\
\hline
\end{tabular}

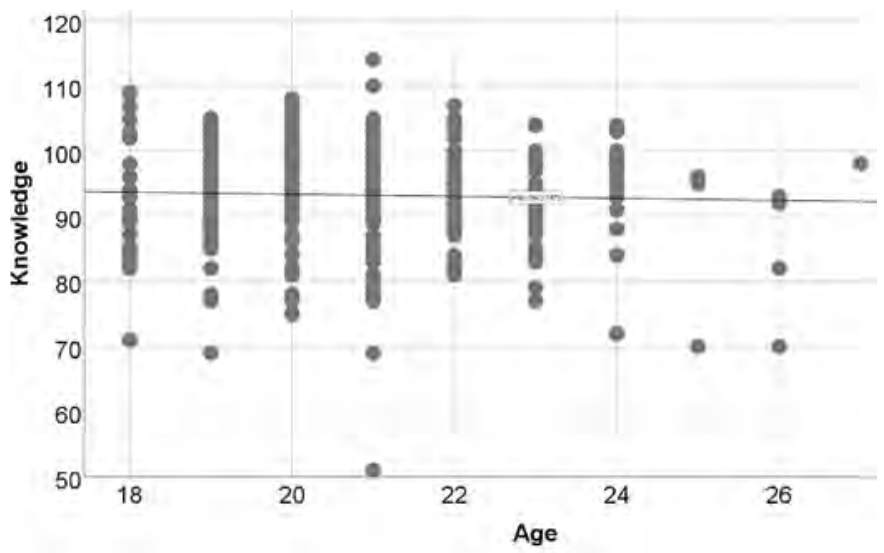

Fig 1: Figure showing linear relationship between age and knowledge score

medication was significantly higher among Nepalese respondents as compared to Indians. Similarly, respondents whose fathers were not in health-related professions had a significantly higher self-medication practice.

Table 4 provides details about the practice of self-medication by the respondents.The most commonly used medicine for self-medication was pain-killers $(n=198,60 \%)$. It was followed by antipyretics, skin ointments, and vitamins and tonics. Antibiotics and anti-allergics were equally used for self-medication. Apart from allopathic drugs, 80 (24.24\%) respondents also self-medicated with ayurvedic drugs. 
Table 3: Prevalence of self-medication practice based on demographic profile $(N=330)$

\begin{tabular}{|c|c|c|c|c|}
\hline \multirow{2}{*}{ Variables } & & \multicolumn{2}{|c|}{ Self medication } & \multirow{2}{*}{ Statistics } \\
\hline & & Yes, $n(\%)$ & No, $n(\%)$ & \\
\hline \multirow{2}{*}{ Gender } & Male & 156 (82.9) & 32 (17) & \multirow{2}{*}{$\begin{array}{c}X^{2}=0.04, d f=1 \\
p=0.84\end{array}$} \\
\hline & Female & 119 (83.8) & $23(16.1)$ & \\
\hline \multirow{2}{*}{ Nationality } & Nepalese & 245 (85.6) & $41(14.3)$ & \multirow{2}{*}{$\begin{array}{c}X^{2}=3.98, d f=1 \\
p=0.04\end{array}$} \\
\hline & Indian & $40(75)$ & $14(25)$ & \\
\hline \multirow{2}{*}{ Family home } & Urban & 227 (82.8) & $47(17.1)$ & \multirow{2}{*}{$\begin{array}{c}X^{2}=0.27, d f=1 \\
p=0.6\end{array}$} \\
\hline & Rural & $48(85.7)$ & $8(14.2)$ & \\
\hline \multirow{2}{*}{ Father's profession } & Health related & $43(74.1)$ & $15(25.8)$ & \multirow{2}{*}{$\begin{array}{c}X^{2}=4.28, d f=1 \\
p=0.03\end{array}$} \\
\hline & Non-health related & 232 (85.2) & $40(14.7)$ & \\
\hline \multirow{3}{*}{ Mother's profession } & Health related & $21(75)$ & 7 (25) & \multirow{3}{*}{$\begin{array}{c}X^{2}=2.25, d f=2 \\
p=0.32\end{array}$} \\
\hline & Non-health related & 139 (85.8) & $23(14.1)$ & \\
\hline & Housewife & 115 (82.1) & 25 (17.8) & \\
\hline \multirow{4}{*}{ Semester of study } & Second & $75(86.2)$ & $12(13.7)$ & \multirow{4}{*}{$\begin{array}{c}X^{2}=2.69, d f=3 \\
p=0.44\end{array}$} \\
\hline & Fourth & $77(80)$ & $19(20)$ & \\
\hline & Sixth & $60(80)$ & $15(20)$ & \\
\hline & Eighth & $63(87.5)$ & $9(12.5)$ & \\
\hline
\end{tabular}

Table 4: Practice of self-medication (Frequency of use of drugs for common health problems, $N=330$ )

\begin{tabular}{|c|c|c|c|c|c|c|}
\hline \multirow{2}{*}{ Drugs } & \multicolumn{6}{|c|}{ Frequency of use of drug, $n(\%)$} \\
\hline & Nearly all the time & Once a week & Every month & Every 3 months & Every 6 months & Total** \\
\hline Painkillers & $3(0.9)$ & $7(2.1)$ & $22(6.7)$ & $71(21.5)$ & $95(28.8)$ & $198(60)$ \\
\hline Skin Ointment & $6(1.8)$ & $7(2.1)$ & $15(4.5)$ & $38(11.5)$ & $38(11.5)$ & $106(32.1)$ \\
\hline Against fever & $4(1.2)$ & $4(1.2)$ & $8(2.4)$ & $60(18.2)$ & $95(28.8)$ & $175(53)$ \\
\hline Anti-allergic & $3(0.9)$ & $4(1.2)$ & $3(0.9)$ & $36(10.9)$ & $45(13.6)$ & $94(28.5)$ \\
\hline Anti-microbials & 0 & $3(0.9)$ & $2(0.6)$ & 39 (11.8) & $47(14.2)$ & $94(28.5)$ \\
\hline Vitamins and tonics & $4(1.2)$ & $5(1.5)$ & $7(2.1)$ & $43(13.0)$ & $34(10.3)$ & $97(29.4)$ \\
\hline Ayurvedic medicines & $6(1.8)$ & $4(1.2)$ & $2(0.6)$ & $25(7.6)$ & 39 (11.8) & $80(24.2)$ \\
\hline Others & $1(0.3)$ & $1(0.3)$ & $3(0.9)$ & 0 & 0 & $7(2.1)$ \\
\hline
\end{tabular}

** The total percentage is more than 100 due to multiple responses to each question

\section{DISCUSSION:}

This study enrolled 330 respondents out of 356 students in basic science and clinical years. The mean knowledge score was 93.2 (maximum score being 125) indicating a good knowledge score. The practice of self-medication among the respondents was found to be high.

Studies regarding self-medication practice and knowledge among medical students have been carried out. A study by Shankar et al. performed on 125 premedical and undergraduate medical students showed mean knowledge score, perception, and total scores of 73.45, 62.75, and 136.2 (maximum possible scores of 105, 95, and 200) respectively. [5] While Gyawali et al. found mean knowledge, attitude, and total score of 74.54, 67.18, and 141.73 (maximum possible scores of 100, 100, and 200 respectively.[1] The results were different from the findings in our study due to difference in the number of statements (25 versus 20 for knowledge assessment). Mehta et al. showed that more than half of the respondents had a good knowledge about self-medication, the attitude was positive and they favored self-medication saying that it was acceptable.[3] On the contrary a study by James et al. showed that the knowledge of the respondents about self-medication was poor, the practice was common and inappropriate however the respondents had adequate knowledge about the benefits and risks of self-medication.[6] Another important 
finding was females had better knowledge of selfmedication compared to males. The knowledge of the Indian respondents was found to be higher than Nepalese in the present study unlike the findings of Gyawali et al. and Shankar et al. where no such association of knowledge with gender or nationality was mentioned.[1,5] In the present study, the Indian respondents accounted for only $16.4 \%$ of the total. This could have had an influence on the results.

In this study, though there was variation in mean knowledge between students of different semesters, they were not statistically significant which is in congruence with the findings by Shankar et al.[5] A study by Gyawali et al. showed that the fourth semester students had better knowledge about self-medication compared to second semester ( $p<$ 0.05 ) and they stated that knowledge increases as the level of education increases.[1] Another study by Sontakke et al. compared the pattern of selfmedication among first and third year medical students which showed that senior students had better knowledge than juniors but the juniors were also well aware about self-medication suggesting medical education can have positive effect on the knowledge about self-medication.[7]

Studies on self-medication practice show a wide range of results with the prevalence ranging from $26.2 \%$ to $92 \%$.[8,9] In the present study, self-medication was practiced by $83.3 \%$ of the respondents which was comparable to the prevalence of $82.3 \%$ and $79.9 \%$ in the study done in India and Serbia respectively.[10,11] The present study showed significant differences in prevalence of selfmedication based on the profession of the father of the respondents. Profession and educational status of father can influence the self-medication practice among their children which might be because of our conservative and patriarchal society similar to the reasons provided in the Serbian research. [11] However, contrary to expectation, a greater proportion of students with fathers not in healthrelated professions self-medicated. Lesser percent of Indians was found to self-medicate compared to Nepalese students in the present study which might be due to the fear of untoward consequences of selfmedication when they are staying away from their home and in the absence of their parents. However, the Indian respondents had a higher knowledge about self-medication compared to their Nepalese counterparts.

Other studies also show increased self- medication practice with progress to higher level of medical education as mentioned by James et al. between second and fourth semester students ( $p=$ $0.02)$, Banerjee et al. between first and fourth year $(p<0.001)$, and another study done in Slovania between first year and final year $(p=0.038)$. $[6,12,13]$ However, the present study did not find any significant differences in prevalence of selfmedication among junior and senior medical students similar to the study done in Aruba by Shankar et al. and Nagpur, India by Sontakke et al.[5,7]

Analgesics was reported as the most widely used group of drugs for self-medication in the study by Mehta et al. (75\%)[3] James et al. (81.3\%),[6] Badiger et al. (71\%),[9] similar to the present study (71.5\%). This trend of analgesic self-use can lead to drug tolerance, dependence (with opioids) and also may mask the actual diagnosis of the underlying disease. The use of antibiotics is also a matter of concern in the present study though the percentage was much lower than that of the studies by Patil et al. and Vedrana et al. where antibiotics have been identified as the most commonly self-medicated group of drugs.[14,15] This may be the outcome of poor implementation of strict regulatory policy on the over the counter sales of antibiotics in those nations.

We recommend that modifications in teaching-learning methodology be planned to increase the level of idea and concept among medical students regarding self-medication so that they can benefit their patients in the future and secure rational practices in their profession.

\section{Limitations:}

Recall bias may be the major drawback as the students were asked to provide the information of drugs used for self-medication during the preceding one year. The present study did not include the respondents from other faculties like nursing. A comparative study could be planned involving different health science faculties regarding selfmedication in LMCTH. Respondents could have interacted with each other while completing the questionnaire.

The high response rate was the strength of the study.

\section{CONCLUSION:}

Undergraduate medical students have a 
good knowledge about self-medication and more than $80 \%$ of them practice it. Painkillers were the most self-medicated drug. This is a very delicate issue in medical profession because these future prescribers are the ones who maintain public trust in pharmacotherapy and contribute to maintaining health of the population.

\section{REFERENCES:}

1. Gyawali S, Shankar PR, Poudel PP, Saha A. Knowledge, Attitude and Practice of Self-Medication Among Basic Science Undergraduate Medical Students in a Medical School in Western Nepal. J Clin Diagn Res. 2015;9:17-22. PMID: 26816912 DOI: $10.7860 / J C D R / 2015 / 16553.6988$

2. Fourth WHO Consultative Group on the Role of the Pharmacist. The role of the pharmacist in self-care and self-medication. Hague, The Netherlands: Department of Essential Drugs and Other Medicines World Health Organization; 1998. 17p. Publisher Full Text

3. Mehta RK, Sharma S. Knowledge, attitude and practice of self-medication among medical students. IOSR J Nurs Health Sci. 2015;4(1):89-96. Publisher Full Text

4. Shankar PR, Partha P, Shenoy N. Self-medication and nondoctor prescription practices in Pokhara valley, Western Nepal: a questionnaire-based study. BMC Fam Pract. 2002;3:17. PMID: 12236905 DOI: 10.1186/1471-2296-3-17

5. Shankar PR, Dubey AK, Dwivedi NR, Nandy A, Barton B. Knowledge, perception and practice of self-medication among premedical and basic science undergraduate medical students. Asian J of Med Sci. 2016;7(6):65-68. DOI: $\underline{10.3126 / a j m s . v 7 i 6.15246}$

6. James H, Handu SS, Al Khaja KA, Otoom S, Sequeira RP. Evaluation of the knowledge, attitude and practice of self-medication among first-year medical students. Med Princ Pract. 2006;15(4):270-275. PMID: 16763393 DOI: $10.1159 / 000092989$

7. Sontakke SD, Bajait CS, Pimpalkhute SA, Jaiswal KM, Jaiswal SR. Comparative study of evaluation of selfmedication practices in first and third year medical students. Int J Biol Med Res. 2011;2:561-564. Publisher Full Text

8. Martins AP, Miranda AC, Mendes Z, Soares MA, Ferreira $\mathrm{P}$, Nogueira A. Self-medication in a Portuguese urban

\section{Competing interest:}

None declared

\section{Financial disclosure:}

No funds were available population: a prevalence study. Pharmacoepidemiol Drug Saf. 2002;11:409-414. PMID: 12271884 DOI: 10.1002/ pds.711

9. Badiger S, Kundapur R, Jain A, Kumar A, Pattanshetty S, Thakolkaran N, et al. Self-medication patterns among medical students in South India. Australas Med J. 2012;5(4):217-220. PMID: 22848313

10. Pandya RN, Jhaveri KS, Vyas FI, Patel VJ. Prevalence, pattern and perceptions of self-medication in medical students. Int J Basic Clin Pharmacol. 2013;2(3):275-280. DOI: $10.5455 / 2319-2003 . i j b c p 20130608$

11. Lukovic JA, Miletic V, Pekmezovic T, Trajkovic G, Ratkovic $\mathrm{N}$, Aleksic D, et al. Self-medication practices and risk factors for self-medication among medical students in Belgrade, Serbia. PLoS One. 2014;9(12):e114644. DOI: 10.1371\%2Fjournal.pone.0114644

12. Banerjee I, Bhadury T. Self-medication practice among undergraduate medical students in a tertiary care medical college, West Bengal. J Postgrad Med. 2012;58:127-131. PMID: 22718057 DOI: 10.4103/0022-3859.97175

13. Klemenc-Ketis Z, Hladnik Z, Kersnik J. Self-medication among healthcare and non-healthcare students at University of Ljubljana, Slovenia. Med Princ Pract. 2010;19:395-401. PMID: 20639665 DOI: $10.1159 / 000316380$

14. Patil SB, Vardhamane SH, Patil BV, Jeevangi SK, Binjawadgi AS, Kanaki AR. Self-mediciation practice and perception among undergraduate medical students: A cross-sectional study. J Clin Diagn Res. 2014;8(12):20-23. PMID: 25653969 DOI: $10.7860 / J C D R / 2014 / 10579.5313$

15. Vedrana AV, Vladimir T, Zdravko L. Content of home pharmacies and self-medication practices in households of pharmacy and medical students in Zagreb, Croatia: findings in 2001 with a reference to 1977. Croat Med J. 2005; 46:74-80. PMID: 15726679 